\title{
Macunaíma ou o Mito da Nacionalidade ${ }^{*}$
}

\author{
Urias Arantes**
}

Resumo: Este ensaio propõe-se a questionar o mito do processo de formação de uma identidade nacional na literatura brasileira, a partir de uma análise de certos aspectos da composição estética do romance modernista de Mário de Andrade, Macunaíma, o herói sem nenhum caráter. $\mathrm{O}$ autor interroga-se em que medida estes aspectos, relativos à sua forma e conteúdo, não revelam uma cisão originária que impossibilita a constituição de uma identidade nacional.

Palavras-chave: mito da identidade - consciência nacional - cisão constitutiva - modernismo - democracia.

Para Celso Favaretto

Gostaria de partir de uma afirmação corrente entre aqueles que se interessam pela coisa brasileira, a saber, que é sobretudo na literatura que encontraríamos as primeiras manifestações - e também as mais eloquentes - de um processo de formação da consciência nacional. Digamo-lo imediatamente: por processo de formação da consciência nacional é preciso entender o processo de busca ou de constituição da identidade; pode-se também entendê-lo como o esforço mais ou menos consciente e refletido para assumir o próprio destino. Assim, a literatura brasileira daria provas de um trabalho de auto-representação, de construção laboriosa de uma imagem de si, e que seria ao

" Como o leitor certamente perceberá, este texto foi não só escrito para um público não-brasileiro, mas também em francês. Por razões que o leitor talvez também compreenderá, o autor teria preferido publicá-lo na língua em que foi concebido. Esta pequena frustração - de natureza retórica - não me impede de agradecer calorosamente ao tradutor, Macunaima ou le mythe de la nationalité foi traduzido por André Duarte.

** Autor de Charles Fourier ou l'art des Passages. 
mesmo tempo um reconhecimento e um projeto - em todo caso, uma imagem da qual se poderia esperar que ela se desse como referência do sensível, do pensável, da ação, do julgamento, do possível etc. Um tal processo seria visível ao menos a partir do fim do século XVIII, com o movimento literário conhecido como "arcadismo", do qual vários nomes participaram do levante projetado para 1789 contra a coroa portuguesa. Encontraríamos aí "as bases de toda uma nacionalidade literária"(1).

É sobre o fundo desta pretensão da literatura brasileira que gostaria de propor algumas reflexões a partir do romance de M. de Andrade, Macunaíma, o herói sem nenhum caráter (1), e do brilhante comentário que lhe consagrou G. de Mello e Souza (4).

Antes de iniciá-las, permitam-me algumas observações preliminares concernentes à questão da identidade nacional, tal como ela se deixa compreender na literatura.

Empreguei mais acima a palavra formação, que me remete à obra clássica de A. Candido, Formação da Literatura Brasileira (3), publicado nos fins da década de 50. Por formação, o autor compreende a "síntese das tendências universalistas e particularistas" (p.25), uma síntese que faz sistema, quer dizer, uma síntese que constitui a literatura como sistema que engloba produtores, receptores e um meio de transmissão, tanto quanto uma tradição em relação à qual o sistema se define. Disto resulta que o sistema é pensado na história, e que ele não se forma senão quando há "uma continuidade ininterrupta de obras e de autores cientes, quase sempre, de integrar um processo de formação literária" (p.27). Isto só aconteceu no Brasil por volta da metade do século XVIII, associando-se desde o início ao esforço para provar ser tão capaz quanto os europeus; após 1822 (data da ruptura oficial com a metrópole pela proclamação da independência), a atividade integra o esforço por construir um "país livre", segundo um programa preestabelecido. Esta grade interpretativa aplicar-se-á ao período de pouco mais de um século, durante o qual se formou a literatura brasileira. 
Este momento da formação, sempre segundo o mesmo autor, comporta essencialmente dois movimentos literários: o arcadismo (neoclassicismo ou ilustração) e o romantismo. Os dois têm em comum a disposição profunda de constituir uma literatura nacional, paralelamente às literaturas européias. Entenda-se por isto uma literatura que seja expressão de uma realidade própria. Nos dois casos, igualmente, os modelos são estrangeiros: e se os românticos reprovam nos arcadistas uma literatura destituída de relação com a realidade brasileira, de fato eles nada mais fazem do que repetir a crítica do romantismo europeu ao classicismo, sem falar dos esforços do romantismo tropical para fundar sobre mitos a legitimidade da nova "nobreza" brasileira.

Ora, onde nosso autor vê uma síntese criadora, é também possível enxergar o signo de uma cisão constitutiva, uma quase-impossibilidade de constituir uma identidade, no sentido do reconhecimento de si no espaço e no tempo. E é mesmo possível que a cisão seja mais "constitutiva" que a síntese que tenderia sempre a ocultar a primeira, a resolvê-la pela negação de sua potência criadora e de movimento.

Sob o título geral de drama espiritual de uma antiga colônia, tento uma primeira formulação desta fratura irredutível: entre um passado com o qual não cessamos de acertar contas, e o desejo de um futuro que nada tenha que ver com este passado, ou mesmo com o presente. Daí que o acerto de contas far-se-ia sempre de maneira um pouco torta: pois tratar-se-ia sempre de denegar o passado, de apagá-lo. Daí resultaria uma presença ainda mais visível deste passado, assim como uma visada do futuro marcada pela forma de uma fuga para frente. Se isto for justo, o presente do drama corre o risco de não ser mais do que uma constante repetição do mesmo, uma espécie de momento intemporal, aquém ou além do tempo, onde gira sempre, apesar das aparências, o mesmo círculo vicioso. Não é surpreendente, então, que a idéia da Revolução se mostre entre nós teimosamente enraizada.

*

Macunaíma, o herói sem nenhum caráter foi publicado em 1928; tornouse um dos livros mais significativos do chamado modernismo, movimento 
estético criado no Brasil, no início dos anos 20 , sob a influência do futurismo europeu. Aliás, futurismo era o nome que ele se dava no início. Não é aqui o lugar para examinarmos as relações complexas que o romance estabelece com o projeto modernista em geral. Basta recordar que, até hoje, a interpretação de Macunaíma parece mais ou menos inseparável da concepção que se tenha do projeto modernista, da modernização, ou, mais geralmente, da história cultural do país e, consequentemente, das perspectivas do porvir. Como se vê, o que está em jogo não é nada desprezível.

Convém descrever rapidamente a trama central do romance na qual se situam certos episódios que analisaremos mais em detalhe. Macunaíma é filho de uma índia; nasceu negro, e nada se diz de seu pai. Ainda criança, pode transformar-se em belo príncipe quando de seus primeiros jogos amorosos. Preguiçoso, mentiroso, maroto, frequentemente ingênuo, mulherengo, suas vontades, grandes ou pequenas, sempre passam por cima de tudo e de todos. Punido por sua mãe por recusar-se a dividir o alimento abundante de que dispõe com seus irmãos, que morrem de fome, ele é condenado a não mais crescer. No mesmo episódio, encontra um animal que lhe lança suco de mandioca sobre o corpo: Macunaíma espirra e cresce imediatamente. Com exceção da cabeça, que não fora molhada. Enganado por um gênio maligno, ele mata sua mãe que fora transformada em cerva; após seu enterro, ele segue pelo vasto mundo com seus dois irmãos e sua companheira. Seu primeiro encontro é com $\mathrm{Ci}$, a mãe do mato, uma amazona que ele domina e viola após um feroz combate, para tornar-se o Imperador do Mato Virgem. Da união nasce uma criança que morre pouco depois. Ci, a mãe, antes de subir ao céu para tornar-se uma estrela, dá a Macunaíma um amuleto. Nova partida do herói que perde a seguir seu amuleto e descobre que a pedra está de posse de um gigante que mora em São Paulo. Daí por diante, o objetivo do herói é o de recuperar seu amuleto, o que acontecerá no fim do romance, após mil aventuras. Encontrada a pedra, Macunaíma retorna a seu ponto de partida, não ao país do qual se tornara imperador, mas ao lugar em que nascera e em que sua mãe fora enterrada. Abandonado pouco a pouco por todos, com exceção de um papagaio a quem ele conta suas aventuras, o herói cai numa armadilha preparada por Vei, o Sol (no romance, trata-se de um personagem feminino), que quer se vingar: num capítulo ante- 
rior, Macunaíma prometera casar-se com uma das filhas do Sol, promessa que esquecera imediatamente ao encontrar uma portuguesa. Vencido, o amuleto definitivamente perdido, seu corpo em pedaços, esgotado e desgostoso deste mundo, o herói não vê mais o sentido das coisas e sobe ao céu para se tornar a constelação da Grande Ursa.

Alinhei os elementos que parecem formar o fio da trama; mas esta contém uma grande quantidade de outros episódios, aventuras, histórias e personagens, extraídos em sua maioria do imaginário popular brasileiro. A interpretação que nos serve de ponto de referência sugere que o romance foi construído segundo a forma literária e popular da rapsódia. Isto implica um problema difícil. De fato, parece que poderíamos privilegiar a multiplicidade dos fatos enquanto tal, sem buscar estabelecer entre eles uma hierarquia. Escolhida esta abordagem, a interpretação poderia então apoiar-se no modo pelo qual se serve o autor para passar de um episódio a outro. Por outro lado, poder-se-ia privilegiar uma seqüência de episódios - uma seqüência cuja constituição seria necessário justificar - e, neste caso, pode-se tentar mostrar como certas tensões trabalham o conjunto da narrativa. De minha parte, tentarei trazer água aos dois moinhos simultaneamente, quer dizer, analisarei dois elementos estruturais concernentes à forma da ligação entre os episódios: penso na organização e na figura do espaço e do tempo na narrativa. A seguir, abordarei mais de perto uma sequêencia de episódios referente às múltiplas partidas do herói.

Como já observei, a interpretação que seguimos aqui explica a embaralhada geográfica do romance pela forma rapsódica escolhida, que consistiria em justapor elementos espaciais, fragmentos de espaço. O resultado seria próximo da mise-en-scène medieval. Curiosamente, entretanto, o palco que o livro construiria é definido como "um aglomerado indiferenciado de lugares 
distintos". A razão estética de uma tal escolha seria o acordo entre a forma rapsódica e a distribuição espacial: à justaposição dos acontecimentos corres. ponderia a justaposição dos fragmentos de espaço geográfico. Mas esta forma do espaço também obedeceria a um "projeto nacionalista do autor de criar a imagem de uma unidade lendária, de uma utopia geográfica". Esta unidade sonhada tomaria o lugar da fragmentação e do isolamento no qual vivem geograficamente os brasileiros. Eis por que o herói faz carreiras malucas, cruza milhares de quilômetros perseguido por um cão, um gigante ou por uma velha gulosa.

No que se refere ao tempo, nossa intérprete sublinha ainda uma vez a estrutura rapsódica, e fala de uma indeterminação temporal caracterizada pela substituição do conceito de vir-a-ser "pela categoria temporal essencial da coexistência". Donde uma temporalidade homogênea, sem divisão e sem ruptura, que destrói as contradições e reestabelece a justiça entre "a civilização técnica do Sul e a cultura agrária e arcaica do Nordeste". Este tempo seria um tempo primordial que concorda com um espaço lendário.

Ora, Macunaíma é evidentemente um livro de grande complexidade formal e temática. A interpretação não deve esgotar a complexidade da obra, mas tentar captar sua natureza e sua condição de possibilidade. Sob este aspecto, a interpretação que aqui nos guia é exemplar, mesmo se ela parece fracassar. De fato, ela confere uma excessiva importância à analogia estrutural e temática do romance com certos processos brasileiros e universais da criação musical. Os argumentos e as análises fundados na analogia são convincentes, e lançam uma nova luz sobre a confecção romanesca. (A crítica endereçada a H. de Campos, por exemplo, parece bem calibrada.) Mas a analogia não poderia fornecer mais que um guia para o leitor, um guia que permite perceber os pontos a interrogar; dificilmente poderia fornecer o sentido específico e provavelmente irredutível da obra. Em outras palavras, se a analogia pode funcionar como um detector das articulações e dos nós decisivos, pode também ocultar a indeterminação própria destes nós de sentido. Assim, nossa intérprete deixa-se guiar pela analogia com a rapsódia a fim de afastar a imagem de um mosaico ou de um bricolage, mas ela não se interroga a respeito do modo próprio da multiplicidade de elementos heterogêneos justapostos. A este respeito, a interpretação 
hesita entre caracterizações divergentes, e mesmo contraditórias. Que a divergência e a contradição sejam próprias ao romance, não há dúvidas; entretanto, o intérprete tem a tarefa de enunciar seu estatuto. E aí, a analogia musical não serve mais como guia. Penso que a pista a seguir seria a seguinte: a rapsódia, como se sabe, é uma seqüência de elementos heterogêneos no que concerne à sua estrutura e caráter, mas que têm em comum o serem todos de tipo coreográfico. Ora, se encontramos em Macunaíma a aposição de elementos heterogêneos, seria ainda preciso interrogar o destino literário de seu traço comum, a saber, que todos eles referem-se ao espaço e ao movimento no espaço. E talvez esta questão não possa ser respondida da mesma maneira que na música. A rapsódia é a forma de composição de muitas danças dramáticas populares brasileiras; é possível que as exigências impostas pelos ritmos corporais em movimento no espaço sejam responsáveis pela justaposição dos elementos heteróclitos, chamados em função da sequêencia do movimento. Que dizer acerca desta força de junção no romance?

Retomemos a temporalidade engendrada pelo romance. É evidente que ela é circular: após ter recuperado seu amuleto, Macunaíma retorna à sua origem, a seu ponto de partida, ao lugar de seu nascimento. É o mesmo que dizer que o herói vive duas vezes o drama da origem, que é, também, a origem do percurso. Entretanto, a solução do drama não é a mesma a cada vez, e podemos mesmo nos perguntar se o próprio drama se repete. Na origem, o drama se resolve com a partida de Macunaíma, com o abandono do lugar de nascimento onde está enterrada a mãe. O capítulo se chama Maioridade. No fim, ou melhor, no retorno, o drama resultará numa espécie de sublimação do herói, uma sublimação a ser tomada quase no sentido químico do termo: passagem do estado sólido ao estado gasoso, pois Macunaíma torna-se a Grande Ursa no capítulo de mesmo nome, antes do epílogo que se refere às condições de existência da narrativa. O primeiro drama tem seu ponto alto na morte da mãe provocada por Macunaíma, que persegue e mata sua mãe transformada em cerva por Anhangá. É após o enterro e o luto que Macunaíma, os dois irmãos e a bela Iriqui saem pelo vasto mundo. Nos dois capítulos seguintes, o herói irá tornar-se o Imperador da Mata-Virgem graças a sua união com uma amazona, a qual lhe dará uma pedra verde cuja perda engendrará a busca que ocupa 
a maioria dos capítulos. Recuperada a pedra, Macunaíma retorna, não a seu império, mas ao país de sua mãe. Pouco a pouco, o retorno se transforma em solidão e numa quase morte do corpo, posto que o herói não despertà senão para narrar suas aventuras a um papagaio. Reanimado e traído pelo Sol, o herói mergulha na água fria, compelido pelo desejo da bela jovem que aí se encontra e que, na realidade, é um monstro. Derrotado, tendo perdido partes de seu corpo, o herói reencontra algumas partes delas, mas decide abandonar a terra: “este mundo não tem jeito mais, e eu vou pro céu!". Os dois dramas assinalam uma ruptura e uma partida e, sob este aspecto, o drama final repete aquele da origem, como a morte repetiria o nascimento: repetição da ruptura. Mas, então, a circularidade temporal não é, propriamente falando, da ordem da coexistência na heterogeneidade. Aqui, diríamos nós, a circularidade vem denegar a história. Tudo se passa como se a ruptura na origem fosse tal que a única possibilidade seria a de repeti-la até o salto para além de toda temporalidade. Não se reestabelece a justiça, os momentos não são iguais; pois há apenas um momento, um único drama encenado e reencenado além de todas as aparências. Um tempo primordial seria um tempo cíclico e, ao mesmo tempo, paradigmático; a repetição seria repetição daquilo que se manifestou numa realidade transcendente. Ora, apesar de todas as aparências, não há transcendência em Macunaíma, mas repetição de uma fratura irredutível, da qual só nos desfazemos na sublimação.

E se agora retomarmos a dimensão espacial do romance, então esta fratura aparece como uma fragmentação, como despedaçamento ou como corpo despedaçado. E é permitido pensar que se o herói não acede à história é porque já de início ele é um corpo não-estruturado. Ele nasceu negro, mas pode a qualquer momento tornar-se um belo príncipe: sua mãe o condena a não mais crescer, mas um pássaro faz com que ele cresça de uma só vez, com exceção da cabeça etc. Esta desarticulação do corpo reflete-se igualmente na geografia imaginária do romance, a qual não nos recorda nem um aglomerado indiferenciado, nem a mise-en-scène medieval. Aliás, estas duas expressões não poderiam ser sinônimas, como dá a entender nossa intérprete; pois a encenação medieval comportava uma hierarquização rígida e imutável dos espaços, em função de seu lugar na concepção cristã do mundo. Em Macunaíma, pelo 
contrário, os fragmentos de espaço abundam, dançam por vezes loucamente, mas nem por isto deixam de ser atraídos por uma espécie de força gravitacional de dois pólos: a cidade e a mata. A cidade domina ao menos quantitativamente, pois sete episódios dão-se em São Paulo, e dois no Rio, dentre os dezessete que compõem o romance, mais um epílogo. Isto não é tudo. Cada pólo funciona como um núcleo de sentido e, apesar de sua oposição, eles se refletem, isto é, remetem um ao outro; daí resulta uma multiplicação de imagens que torna impossível distinguir o que não seria da ordem da imagem refletida. O repouso sobre um objeto "real" não existe, as imagens se multiplicam, se alucinam, às vezes se espalham para polarizarem-se a seguir. De sorte que se pode falar de uma espécie de reflexão espacial como forma de distribuição espacial de Macunaíma.

Se aceitarmos que o espaço é uma realidade de algum modo mais fundamental, mais primordial que o tempo, e que a temporalidade não se constitui senão sobre uma estrutura espacial já estabelecida, então será preciso admitir que Macunaíma é um romance da nacionalidade no sentido de tratar da préhistória ou das condições de impossibilidade da nacionalidade como figura histórica. A fragmentação espacial e suas polarizações revelam-se, na ordem da temporalidade, como uma ruptura, como uma fratura originária que faz do tempo não o tempo da transformação, do vir-a-ser e do acontecimento, mas o tempo - da repetição da origem, da fratura originária. Esta então aparece não como um acidente advindo à uma substância de outro modo plenamente em si, mas como constitutiva da substância, como seu ser. O que o romance nos diz a respeito da nacionalidade é que a busca de um signo, no qual poderíamos enfim nos reconhecer plenamente, com o qual poderíamos finalmente nos identificar, é uma busca destinada ao fracasso. Não porque inexistam tais signos, mas porque a própria busca, assim como seu fracasso, constituem já o signo. Mas, de fato, signo de quê? Signo, possivelmente, de uma fratura originária cujo efeito essencial, cruel e de certo ponto de vista trágico, é a ausência de um referente no qual a potência multiplicadora do signo possa 
encontrar seu termo. O romance ativa esta fratura originária e esta dispersão e multiplicação constitutivas plenamente como fratura e dispersão, introduzindo justamente a literatura: após um momento-papagaio, de pura reprodução, o literário emerge como criação de um discurso humano, um discurso próprio e o que é próprio ao discurso é fazer dançar os fragmentos de toda espécie, segundo uma lógica da multiplicação dos espelhos. Também se pode falar de Macunaíma como o romance da repetição. Será preciso voltar à questão.

Mas, se quisermos formular esta questão da ruptura originária mais detalhada e profundamente, devemos analisar o episódio da alucinação de Macunaíma, justamente destacado por nossa intérprete. O fragmento encontra-se quase ao final do livro, num capítulo anterior àquele em que Macunaíma enfim recupera seu amuleto. Pouco antes, o herói havia planejado partir com seus irmãos para a Europa, a fim de procurar o gigante ainda de posse de sua pedra. Eles possuem o dinheiro para financiar a viagem, mas os irmãos insistem para que Macunaíma requeira uma bolsa de estudos ao governo. Esperando a resposta de seu pedido, Macunaíma se deixa enganar por um ladrão e perde todo seu dinheiro; a bolsa de estudos não virá e, cheio de despeito, o herói exclama, sapateando sobre suas calças: "Paciência, manos! não! não vou na Europa não. Sou americano e meu lugar é na América. A civilização européia decerto esculhamba a inteireza de nosso caráter!”. Logo a seguir, Macunaíma cai doente e sonha com um barco, signo premonitório da viagem. Convalescendo, vai passear no centro da cidade onde, cansado, senta-se à beira de uma fonte consagrada a Carlos Gomes, "um músico muito célebre e que agora era uma estrelinha no céu". É do fundo de uma gruta, atrás da fonte, que o herói vê aproximar-se um barco; ele se torna cada vez maior, até se transformar num transatlântico luxuoso em rota para a Europa. Os gritos de Macunaíma despertam os choferes de táxi, que formam um pequeno grupo ao qual o herói se dirige: "Adeus! adeus, gente! Vou prá Europa que é melhor! Vou em busca de Venceslau Pietro Pietra que é o gigante Piaimã, comedor de homens!”. Os passageiros do navio - marinheiros forçudos, argentinos finíssimos e donas 
lindíssimas - o saúdam e o chamam. Quando Macunaíma pede ao capitão do navio para descer-lhe a escada, este faz um sinal e os passageiros começam a caçoar do herói. O navio se distancia lançando sobre Macunaíma uma nuvem de insetos, que também dispersa o público. O episódio é apresentado como uma tentação da Mãe d'Água.

Segundo o comentário que acompanhamos, a alucinação põe em cena a ambivalência do personagem, dividido entre sua fidelidade à Europa e ao Brasil. De fato, a ambivalência existe e o romance a expõe longamente e com muitos detalhes. Mas é necessário interrogar os elementos fornecidos pelo romance para compreender a natureza desta ambivalência. Certamente não há em Macunaíma nenhuma "fábula normativa", mas talvez haja um pouco mais do que a simples afirmação analítica da ambivalência. O que se percebe quando se brinca com os fragmentos.

Pois, na realidade, há quatro "partidas" em Macunaíma, e nada impede que as consideremos através dos reflexos de umas sobre as outras. A série de reflexões assim reconstruída nos propõe um esquema de interpretação romanesca, um esquema que também pede para ser interpretado.

A primeira partida é aquela que ocorre após o assassinato da mãe. É Macunaíma que, sem saber, mata sua mãe. Mas há também razões objetivas. Aliás o herói havia antecipado o acontecimento. Há um elemento de vingança no assassinato da mãe, pois ela não quis permanecer ao lado de Macunaíma num momento de abundância de alimentos, excluindo os irmãos; pior ainda, ela punira a "maldade" de Macunaíma: ele não deveria crescer mais e seria abandonado na mata. Após o encontro com o pássaro que o faz crescer, o herói retorna à sua família e anuncia a morte de sua mãe. No anúncio, há também um outro elemento que não se refere à vingança: a mãe deve morrer pelo próprio fato de ter dado à luz a Macunaíma. É como se o nascimento não pudesse dar-se senão acompanhado da morte daquela que deu à vida, reestabelecendo deste modo um equilíbrio na economia do mundo. O nascimento e a morte são fatos brutos da natureza. O elemento de vingança não é estranho a esta espécie de justiça natural, pois Macunaíma acusa sua mãe de o haver separado dela, o que representa igualmente o nascimento, o devir dois de um. O equilíbrio que a morte vem então estabelecer é o da unidade consigo mesmo; ao mesmo tempo, 
a morte da mãe põe fim à possibilidade mesma de uma reunificação. A violência extrema do drama, reforçada pela crueldade que mostra Macunaíma na morte da cerva/mãe, é tanto maior pois que não há um terceiro termo em jogo. Esta violência aparece, aliás, sempre que se trata de um acasalamento na mata; por exemplo, na violação de Ci. Esta fratura originária é constitutiva do herói; Macunaíma sentirá toda a sua existência como uma perda, como uma falta, como impossibilidade de unidade e, consequentemente, de identidade. Seu percurso romanesco será o esforço por compensar, apagar, reduzir esta fratura sem que jamais esteja em questão um terceiro termo. Não o esqueçamos, Macunaíma não tem pai; nenhuma lei virá regrar a satisfação de seu desejo. Seu desejo erra. Há aí toda uma metáfora da história da nação como impossibilidade de se constituir enquanto nação.

A segunda "partida" intervém após uma série de três acontecimentos: o filho que Macunaíma tem com a amazona morre, vítima de um envenenamento do leite materno. Para este filho, o herói tinha um projeto de vida: que ele fosse a São Paulo e ganhasse muito dinheiro. Enterrada a criança, Ci dá o amuleto ao herói e sobe ao céu. A errância enlutada de Macunaíma, sempre seguido de seus irmãos, ganha um sentido quando ele perde seu amuleto, fetiche de $\mathrm{Ci}$ e dele mesmo. O gigante que está de posse da pedra mora em São Paulo, e é para lá que se dirige o herói. A fratura originária é aqui, de algum modo, atenuada em sua violência, e pode engendrar um projeto de vida: a busca do fetiche, que lhe permitirá voltar a ser si mesmo refletido neste fragmento da mulher amada. Vemos aparecer aqui outras dimensões da fratura, sob a forma da oposição mata/cidade, amplamente desenvolvida no romance. Interiorizada, aliás, a fratura é o motor de uma busca da identidade considerada então como perdida. $\mathrm{O}$ jogo do interior e do exterior é aqui bastante complexo, pois um remete ao outro. Retenhamos apenas que o drama originário, insolúvel, pode então ser formulado em termos da busca da identidade, pondo em cena o desejo da unidade. Entretanto, é claro que o desejo, nestas condições, também põe em cena a interdição de sua plena realização, donde todas as ambigüidades do herói ao longo de sua procura. A busca da identidade considerada como algo roubado é desde o início destinada ao fracasso. 
A mise-en-scène do desejo com sua própria interdição será representada plenamente na terceira "partida" de Macunaíma: trata-se do projeto e da alucinação de uma viagem à Europa. Aqui, igualmente, nos damos conta de que a atenuação do drama originário não implica, no romance, o esquecimento de sua essencialidade; esta se manifesta, agora, sob a forma de uma oposição entre a América e a Europa. É o drama em sua dimensão política e cultural, do qual o fragmento mais rico é a Carta aos Icamiabas, epicentro do romance, e que será preciso reler, um dia, com atenção. Esta terceira partida, que não ocorre, se desdobra em dois momentos: o projeto e a alucinação. O projeto fracassa, como sabemos, e seu sentido será de fato revelado na alucinação, que mostra bem o prestígio e a distinção sociais representados pela viagem à Europa. Na alucinação, a partida é rodeada por pessoas simples, os choferes; o navio é luxuoso, os companheiros de viagem são refinados, belos e fortes. Que a viagem seja melhor se realizada com dinheiro público é porque, deste modo, a distinção será publicamente reconhecida. A alucinação também mostra o que é a Europa, para nós: ela é da ordem do fantasma, funcionando como um critério interno, para uso interno, de distinção, sendo mais importante a viagem à Europa, e não tanto aquilo que se vai fazer ou obter. E que Macunaíma sonhe em ir procurar sua identidade e resolver seu drama na Europa, eis o que torna a viagem o pólo de todos os sonhos de distinção. Aqui, a mise-en-scène do desejo como mise-en-scène de sua interdição está plenamente acabada. Sabe-se que o autor jamais viajou para a Europa; talvez ele tenha elaborado o fantasma desta viagem melhor do que qualquer outro, tendo compreendido que sua força vinha justamente de seu estatuto fantasmático. Um fantasma só é verdadeiramente esclarecedor quando permanece um fantasma e é tomado enquanto tal; pois ele então revela sua potência de criação e de ilusão. Sua mentira é sua verdade. A questão complexa da identidade nacional aqui encontra o seu lado enigmático, que erramos ao reduzir simplesmente ao ideológico.

A quarta "partida", enfim, a ascensão de Macunaíma ao céu, e sua transformação na Grande Ursa, fecha de certa forma o círculo. É a solução romanesca do drama em todos os śeus desdobramentos. O percurso do herói ganha, finalmente, um sentido; seu desejo é enunciado e, por isso mesmo, transformado. O conjunto da série reflete-se então de outra forma, sem contudo 
negar as reflexões anteriores. Ao contrário, elas são multiplicadas até alcançarem um ritmo vertiginoso. Tendo recuperado sua identidade, o herói retorna triunfante às origens, não ao império do qual ele é o imperador, mas ao lugar de seu nascimento. Este retorno torna-se cada vez menos glorioso e, ao fim, o herói está só e doente. Resta-lhe apenas um papagaio, a quem Macunaíma narra seus feitos. O Sol (feminino no romance) trama a derrocada do herói para vingar-se dele, que prometera casar-se com uma de suas filhas, deixando-a logo a seguir por uma portuguesa. A armadilha é uma mulher sedutora que chama o herói do fundo de um lago. Compelido pelo desejo e pelo calor, o herói mergulha e trava-se um combate. Macunaíma consegue sair da água, mas seu corpo está despedaçado e o amuleto perdido para sempre. O herói ainda consegue reunir alguns pedaços de seu corpo, mas a integridade está comprometida. Abatido pela perda da pedra, e por tantos males, o herói se coloca um dilema: permanecer na terra ou subir ao céu. Permanecer exige aquilo que ele jamais teve: "a coragem pra uma organização". Sua vida não fora senão um "deixar viver", e ficar exige um sentido. Faz-se a escolha: Macunaíma parte rumo ao céu para tornar-se o "brilho bonito mas inútil de uma estrela". Por mais inútil que seja, ao menos, o brilho é o mesmo no qual todos os homens que viveram, vivem ou viverão podem reconhecer-se. Ele faz da humanidade uma grande família em que todos podem fundir sua diferença e, assim, reencontrar o que os entrelaça, reconhecendo o que é comum a todos. Antes de subir ao céu, antes da sublimação finalmente pacificadora, Macunaíma escreve sobre uma pedra o seu epitáfio: "Não vim no mundo para ser pedra" - um epitáfio que responde e se opõe ao enterro de sua mãe "sob uma pedra", enterro sem brilho, no qual ninguém poderia reconhecer-se. Subindo ao céu, separando-se do mundo e de seus combates circulares e repetitivos, o herói consegue encontrar-se com o todo humano na figura do reconhecimento; deixa de ser um fragmento isolado que dança e rodopia, mas faz parte do brilho comum que enlaça todos os homens na fusão familial. O reconhecimento é da ordem da fusão. O desejo do herói é assim revelado, enunciado, e confere às suas "partidas" um novo sentido: tratava-se sempre de partir porque retornar era impossível, mas também para poder retornar, para apagar a fratura. Sendo esta constitutiva, é a própria individuação que deve ser apagada. A individua- 
lidade, a identidade que o amuleto lhe concedera não era suficiente; de fato, ela escondia a violência do drama originário. No combate com a deusa das águas, em sua derrota e em seu despedaçamento, representa-se plenamente o drama do qual o herói tentara escapar. A repetição do drama permite então que o dilema se exponha em toda sua força, sem que nenhum compromisso possa atenuá-lo: é necessária a coragem de dar um sentido ou fundir-se no banho fusional do um. A ausência de um terceiro termo torna-se evidente, funcionando mesmo como uma espécie de interdição absoluta: a reunificação não pode se dar senão como sublimação. Transformado na Grande Ursa, uma constelação próxima do Pólo Norte, pouco visível do hemisfério Sul, o herói congelar-se-á para sempre num lugar-nenhum, único lugar em que pode ganhar figura a utopia da fraternidade universal.

Não há conclusão verdadeira para estas análises. Ao menos é possível ińdicar algumas das articulações e dos desdobramentos que elas tornam possíveis, ou que elas exigem. A análise do espaço e do tempo, tanto quanto a mise-en-scène das "partidas" de Macunaíma, permitiram entrever o sentido geral daquilo que bem podemos chamar de mito da nacionalidade brasileira. $\mathrm{O}$ romance de M. de Andrade é habitado por uma potência multiplicadora que nos conduz ao limite do enigmático, sem jamais abandonar o esforço por enunciálo. Ele sugere que este enigma não poderia ser aprisionado numa única articulação, por mais complexa que seja. Se as levarmos a sério, as questões que daí brotam não se deixam reduzir ao jogo sedutor dos conceitos. Macunaíma funciona como um caleidoscópio, o que não quer dizer de modo algum que todas as suas interpretações sejam relativas a um ponto de vista. Talvez o essencial seja ler o romance à luz de nossas próprias questões, tentando formulá-las à luz do romance: ambos podem então manifestar sua força. O preço do pensamento é aparentemente uma ausência de solo, seja ele conceitual ou de outra natureza, no qual ancorar certezas.

Macunaíma põe em cena as múltiplas vias da questão de uma identidade brasileira, sem jamais cair na armadilha do nacionalismo. E a armadilha é 
evitada justamente pela multiplicação das vias e registros da formulação da questão, de modo que nenhuma resposta vem dominar sua potência de interrogação. Ao multiplicar o jogo reflexivo dos fragmentos de um desejo de unidade, de um desejo de plena posse de si, o autor multiplica também o jogo complexo da interdição do desejo. O enigma está aí, nesta dupla remissão que não engendra unidade, na fratura originária constitutiva, fonte da fragmentação e, por isto mesmo, irredutível a cada uma delas ou à sua totalidade. A encenação do desejo e da interdição é desdobrada, ou melhor exibida, pois não há história progressiva. O fim repete, sob este modo, o começo. Mas há a literatura, e a repetição não é o retorno simples do mesmo. Neste nível, é preciso reconhecer que o romance comporta uma "solução" de ordem "estética": uma criação passando necessariamente pela repetição. Antes do narrador, há o papagaio. A literatura torna-se o equivalente "formal" da sublimação heróica e revela sua função social como lugar do encontro e do reconhecimento de todos os homens. Eis aí o seu "brilho bonito mas inútil".

Resta que a "solução estética" não recobre inteiramente o campo problemático aberto; ao contrário, ela revela outras dimensões. O dilema entre o Céu e a Terra, última figuração da fratura originária ou da origem como fratura, revela a amplitude, diria eu quase-ontológica, da fratura e da ausência do pai. $\mathrm{Na}$ ausência deste terceiro termo, na ausência da dimensão da lei, a fratura congela-se e repete-se face ao desejo incomensurável da fusão na unidade. Não que o pai viesse a preencher o vazio ou a fornecer a via segura para a pacificação do desejo. Pode-se mesmo pensar que ele representa o estragaprazeres, que ele complica o desejo; mas sobretudo talvez ele imponha, por sua própria presença, o reenvio a si de cada um dos dois outros pólos. Ao fazê-lo, a busca da identidade, do próprio, a procura da identidade nacional, não pode desembocar na universalidade sem manter igualmente vivo o desejo de construir o sentido próprio e separado. A ausência do pai/lei deixa o caminho aberto à fusão. $\mathrm{O}$ mito da nacionalidade deve ser compreendido como um fracasso, pois a ausência de lei impede que o separado, que o que não pode existir senão enquanto separado, e cuja existência é separação, reconheça-se como separado mesmo fazendo parte de uma comunidade - ou, melhor dizendo, a ausência da lei impede que o separado reconheça sua Gesellschaftlichkeit. A lei teria 
impedido a fusão no magma fraterno, permitindo a Macunaíma reconhecer sua finitude. O mito da nacionalidade, agora no sentido de ilusão criadora, é aquele da imortalidade, do todo-poderio. Resta que este mito, pelo que ele põe em cena, e pelo que ele oculta, também é o fundamento da coisa brasileira, que aparece então como busca e negação de si, desejo do um e do múltiplo, desejo de eternidade e de morte, com o traço essencial de que, aqui, a aporia não faz história, na ausência de passagem de um termo no outro. O que apenas um terceiro termo pode tornar possível.

Frequentemente nos perguntamos por que, mesmo quando em aparência todas as condições estão dadas, o Brasil parece não poder aceder à democracia. Macunaíma nos tornaria sensíveis a uma falta essencial, a uma falta na essência e no modo próprio à coisa brasileira de preenchê-la. Ora, como conceber a democracia sem a dimensão da lei?

Isto não é uma resposta, mas a abertura para novas questões.

Strasbourg, maio de 1992.

Abstract: From an analysis of some aesthetical aspects of Mario de Andrade's modernist romance, Macunaima, the hero without character, this essay is meant to inquire the myth of a national consciousness and its process of formation through the brasilian literature. The author interrogates if that aesthetical aspects, related to the form and matter of the romance, do not reveal an original scission that hinders the constitution of a national identity.

Keywords: myth of identity - national consciousness - constitutive scission - modernism democracy.

\section{Notas}

(1) A expressão é de O. de Andrade (2). 


\section{Bibliografia}

1. Andrade, Mário. Macunaíma, o herói sem nenhum caráter. São Paulo, Martins, 1978.

2. Andrade, O. A Arcádia e a Inconfidência. In: Obras Completas. Do Pau-Brasil à Antropofagia e às Utopias. Rio de Janeiro, Civilização Brasileira, 1976, $2^{a}$ ed., vol. VI.

3. Candido, Antonio. Formação da Literatura Brasileira. São Paulo, Martins, $1964,2^{\text {a }}$ ed., 2 vols.

4. Mello e Souza, G. O Tupi e o Alaúde: Uma interpretação de Macunaíma. São Paulo, Duas Cidades, 1979. 